\title{
A Humanização nas Ações Educativas Realizadas em uma Unidade Básica de Saúde no Município de Lagarto/ SE
}

\author{
Araujo, Jamilly Santos; Araujo, Jamilly Santos; Almeida, Thaynara Fontes; Fontes, Mírzia \\ Lisboa; Andrade, Maísa Alves; Bispo, Maycon Santana; Barreiro, Maria Socorro Claudino \\ Universidade Federal de Sergipe — jamilly142009@hotmail.com
}

\begin{abstract}
INTRODUÇÃO: a educação em saúde surgiu nos Estados Unidos da América no ano de 1909, em que, baseava-se na transmissão do conhecimento e na domesticação das pessoas, e se fundamentava na perspectiva de responsabilizar a população pelos seus problemas de saúde. o ministério da saúde, desde a década de 1980 vem trazendo estes caminhos e tentando mudar os enfoques das ações educativas. Essas ações passaram a ser vistas como um processo capaz de desenvolver a reflexão e a consciência crítica das pessoas, principalmente sobre as causas de seus problemas de saúde, devendo ser centrada na problematização e na leitura das diferentes realidades, valorizando as experiências de indivíduos e grupos sociais. As atividades educativas são fundamentais para o desenvolvimento humano, visto que, elas além de prevenir, promovem a saúde. a educação em saúde serve para levar o conhecimento para a sociedade, deixando-a informada para o cuidado a sua saúde. OBJETIVO: Desenvolver assistência por meio de ações educativas, integrais e interdisciplinares a usuários de unidade básica do munícipio de Lagarto-SE. METODOLOGIA: relatar a atividade após consultas de pré-natal, em que foi desenvolvida ação de educação em saúde para as futuras mães. RESULTADO: Após a consulta de pré-natal os alunos de enfermagem organizaram uma atividade educativa - palestra dinamizada em que, foi abordada a temática do aleitamento materno a futuras mães. Antes da palestra foi feita uma apresentação das gestantes e investigado o que elas entendiam sobre o aleitamento. As mesmas relataram que amamentação é muito importante nos primeiros seis meses de vida do bebê e que durante esse período não era necessário adicionar outros alimentos. Também, foram abordadas quanto ao adicionamento de outros líquidos e uma das gestantes disse, que poderia dar água e chás nos primeiros seis meses e o leite materno. Outras disseram que o leite materno tinha a quantidade suficiente do que seria necessário para o bebê, pois havia escutado de outras mulheres, que já haviam amamentado. Após a discussão com as futuras mães, foi iniciada a palestra e pontos como: importância, amamentação exclusiva, cuidados com a mama, tempo certo para adicionar outros alimentos na dieta do bebê e composição do leite materno, logo após a apalestra, foi desenvolvida uma dinâmica a qual se prosseguiu com a realização de perguntas para que as gestantes, com intuito de observar se foi possível alcançar um feedback positivo. CONSLUSÃO: a atividade educativa torna a assistência mais humanizada, em virtude de fornecer uma atenção não apenas voltada para o cuidado, mas também na prevenção e promoção da saúde, contribuindo assim para um melhor desenvolvimento da criança nos seis primeiro meses de sua vida. 1-BERNARDES, Maria Eliza Mattosinho. Atividade educativa, pensamento e linguagem: contribuições da psicologia histórico-cultural. Psicol. Esc. Educ., Maringá , v. 15, n. 2, 2011. Disponível em: http://dx.doi.org/10.1590/S1413-85572011000200014. Acesso em 18 de janeiro de 2014. 2- NAKANO, Ana Márcia Spanó; MAMEDE, Marli Villela. a prática do aleitamento materno em um grupo de mulheres brasileiras: movimento de acomodação e resistência. Rev. Latino-Am. Enfermagem [online], vol.7, 1999. Disponível em: http://dx.doi.org/10.1590/S0104-11691999000300010. Acesso em 08 de novembro de 2013.
\end{abstract}

Araujo, Jamilly Santos; Araujo, Jamilly Santos; Almeida, Thaynara Fontes; Fontes, Mírzia Lisboa; Andrade, Maísa Alves; Bispo, Maycon Santana; Barreiro, Maria Socorro Claudino. A Humanização nas Ações Educativas Realizadas em uma Unidade Básica de Saúde no Município de Lagarto/ Se. In: Anais do Congresso Internacional de Humanidades \& Humanização em Saúde [= Blucher Medical Proceedings, num.2, vol.1]. São Paulo: Editora Blucher, 2014. ISSN 23577282

DOI 10.5151/medpro-cihhs-10585 